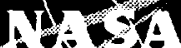

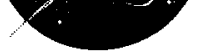

\title{
Transient Thermal Analysis of a Refractive Secondary Solar Concentrator
}

Steven M. Geng

Glenn Research Center, Cleveland, Ohio

Robert P. Macosko

Analex Corporation, Brook Park, Ohio

Prepared for the

34th Intersociety Energy Conversion Engineering Conference sponsored by the Society of Automotive Engineers

Vancouver, British Columbia, Canada, August 1-5, 1999

National Aeronautics and

Space Administration

Glenn Research Center 


\section{Acknowledgments}

The authors wish to recognize Donald R. Buchele, Wayne A. Wong, and Eric L. Golliher for their technical contributions to this paper. Buchele derived a technique for calculating the IR radiation loss from the engine receiver cavity through the flux extractor and concentrator that was used to calibrate the ANSYS ${ }^{\mathrm{TM}}$ thermal model. Wong performed an optical analysis of the solar flux transmitted through the concentrator/flux extractor to determine the flux distribution along the inside surface of the engine receiver cavity. This flux distribution was used as a thermal flux boundary condition in the thermal model. Golliher verified Buchele's IR radiation loss technique using a NEVADA ${ }^{\mathrm{TM}}$ ray trace model.

This report contains preliminary findings, subject to revision as analysis proceeds.

Trade names or manufacturers' names are used in this report for identification only. This usage does not constitute an official endorsement, either expressed or implied, by the National Aeronautics and Space Administration.

Available from

NASA Center for Aerospace Information 7121 Standard Drive

Hanover, MD 21076

Price Code: A03
National Technical Information Service 5285 Port Royal Road Springfield, VA 22100 Price Code: A03 


\title{
Transient Thermal Analysis of a Refractive Secondary Solar Concentrator
}

\author{
Steven M. Geng \\ National Aeronautics and Space Administration \\ Glenn Research Center \\ Cleveland, Ohio 44135 \\ Robert P. Macosko \\ Analex Corporation \\ Brook Park, Ohio 44142
}

\section{Summary}

A secondary concentrator is an optical device that accepts solar energy from a primary concentrator and further intensifies and directs the solar flux. The refractive secondary is one such device; fabricated from an optically clear solid material that can efficiently transmit the solar energy by way of refraction and total internal reflection. When combined with a large state-of-the-art rigid or inflatable primary concentrator, the refractive secondary enables solar concentration ratios of 10,000 to 1 . In support of potential space solar thermal power and propulsion applications, the NASA Glenn Research Center is developing a single-crystal refractive secondary concentrator for use at temperatures exceeding $2000 \mathrm{~K}$. Candidate optically clear single-crystal materials like sapphire and zirconia are being evaluated for this application.

To support this evaluation, a three-dimensional transient thermal model of a refractive secondary concentrator in a typical solar thermal propulsion application was developed. This paper describes the model and presents thermal predictions for both sapphire and zirconia prototypes. These predictions are then used to establish parameters for analyzing and testing the materials for their ability to survive thermal shock and stress.

\section{Introduction}

Design operating temperatures for proposed solar thermal power and propulsion systems are at levels in excess of $2000 \mathrm{~K}$. These high temperature systems have driven the requirement for the sun collection system to achieve geometric solar concentration ratios (CR) to levels that cannot be achieved by a primary concentrator alone. The CR is the ratio of the primary concentrator sun collection area to the entrance aperture area of the heat receiver. The receiver aperture area significantly affects the amount of infrared radiation that escapes from the receiver cavity at these high temperatures, thus for efficient high temperature applications, an optical system with a high concentration ratio is a necessity. Large primary concentrators (rigid or inflatable) cannot focus to the accuracy required and therefore secondary nonimaging concentrators must be included in the system design.

A significant amount of research and development has been completed on nonimaging reflective secondary concentrators (ref. 1). The innovative refractive secondary concentrators (RSC) fabricated of solid high index of refraction materials have been identified as the preferred option on achieving maximum CR (ref. 2). In addition, they have the potential to he the most efficient since they take advantage of essentially loss-free total internal reflection (TIR) to concentrate the solar energy. It has also been reported that in order to achieve a high solar energy throughput efficiency ( $>90$ percent) a flux extractor must be incorporated and made integral to the refractive secondary. The flux extractor reduces the amount of back reflection and allows for flux tailoring via the adjustment of the facet geometry. Unlike the reflective secondary, which discharges most of the energy at the front of the engine cavity, the refractive secondary with flux extractor allows for uniform solar flux distribution further into the cavity, avoiding hot spots.

Reference 3 presents the results of a feasibility study funded by NASA Glenn that describes the concentrator and flux extractor design that is required to support a typical solar thermal propulsion application. This concept (shown in fig. 1) was used as the basis to develop the thermal model described herein.

This paper presents a transient thermal model of a refractive secondary concentrator in a typical solar thermal propulsion application. Although the model was developed for a specific solar propulsion application, the results 


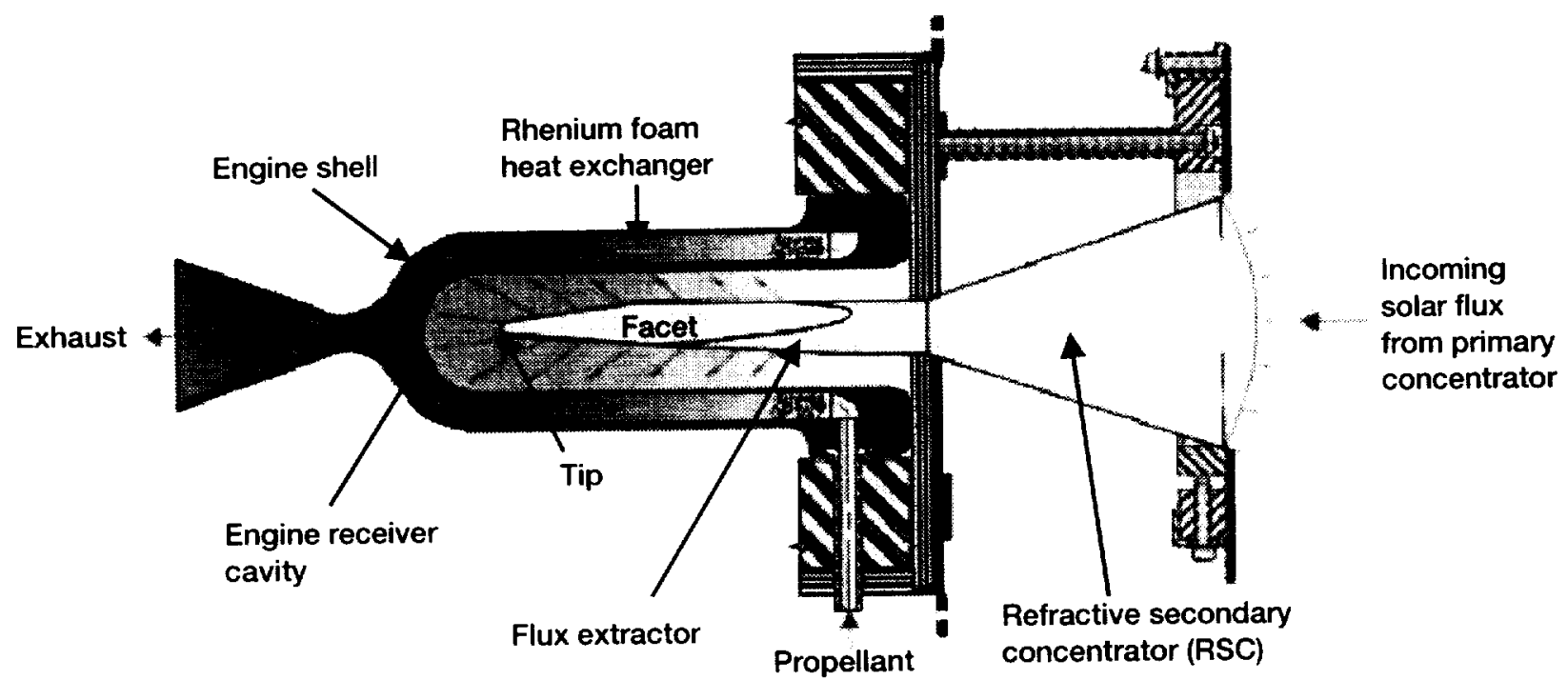

Figure 1.-Cross-sectional view of typical solar thermal engine with integral refractive solar secondary.

generally apply to any high power, high temperature solar application using refractive secondary concentrators (such as power generation or solar furnaces). Model predictions for both zirconia $\left(\mathrm{ZrO}_{2}\right)$ and sapphire $\left(\mathrm{Al}_{2} \mathrm{O}_{3}\right)$ prototypes are presented. The same geometry and boundary conditions were used for the sapphire model and the zirconia model. The geometry was optimized for zirconia. It should be noted that an RSC design optimized for sapphire would have a slightly different geometry and boundary conditions than a design optimized for zirconia due to differences in the thermophysical and optical properties of the two materials. The predictions show how temperature gradients are developed in the refractive secondary. The transient thermal performance information was used to establish test criteria for thermal shock testing on candidate materials. The results of this testing are reported in reference 4 .

\section{Description of RSC Thermal Model}

A three-dimensional thermal model of the RSC and flux extractor was developed using the ANSYS ${ }^{\text {IM }}$ finite element analysis software, version 5.5.1SP. The thermal model also includes the engine receiver cavity, rhenium foam heat exchanger, engine shell, and multilayer insulation (MLI). To simplify the model, the rhenium foam heat exchanger and engine shell were lumped together into an equivalent thermal mass, as shown in figure 2 . There is no direct thermal link between the heal exchanger and engine shell with the concentrator/extractor due to the presence of the engine receiver cavity. The equivalent thermal mass and the engine receiver cavity communicate thermally via conduction.

Basically, solar energy from a primary concentrator (not shown) enters the RSC at a 22 degree entrance half angle. The RSC is shaped such that the entering rays are limited to angles that maintain TIR in the concentrator and the cylindrical end of the flux extractor. The solar energy exits the extractor at three faceted surfaces where it then impinges upon the inside surface of the engine receiver cavity. As the receiver cavity gets hot, the IR radiation from the eavity surface increases. This energy finds its way out of the cavity via transmission through the flux extractor and RSC. At temperatures required for propulsion, the IR radiation becomes the dominant energy loss from the receiver. A small amount of tlux radiates back to the surface of the flux extractor where it is conducted through to the RSC and radiates from the inlet surface.

ANSYS ${ }^{T M}$ models black body and gray body radiation heat transfer; however. ANSYS ${ }^{\text {TM }}$ currently does not model radiation transmission through solids. Boundary conditions and an IR loss submodel were used to compensate for this limitation. In general, the boundary conditions assumed by the model were selected to provide the worst case (highest) crystal temperatures and (largest) temperature gradients. Descriptions of the boundary conditions and IR loss submodel are provided below. 


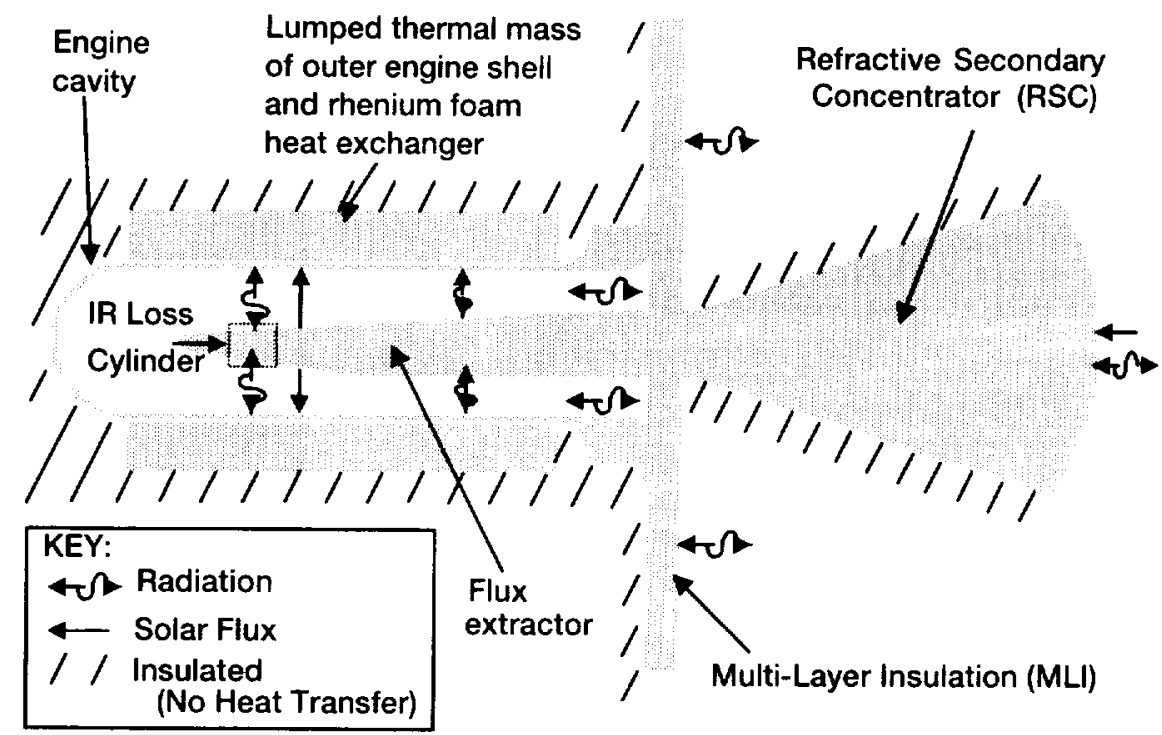

Figure 2.-Schematic diagram of refractive secondary concentrator thermal model.

TABLE I.-MATERIAL PROPERTIES

\begin{tabular}{|c|c|c|c|c|c|}
\hline Matcrial & $\begin{array}{c}\text { Temperature, } \\
{ }^{\circ} \mathrm{C}\end{array}$ & $\begin{array}{l}\text { Thermal } \\
\text { cond.. } \\
W / \mathrm{m}^{\circ} \mathrm{C}\end{array}$ & $\begin{array}{c}\text { Density. } \\
\mathrm{kg} / \mathrm{nm}^{?}\end{array}$ & $\begin{array}{c}\text { Specific } \\
\text { heal. } \\
\mathrm{J} / \mathrm{kg}^{\circ} \mathrm{C}\end{array}$ & Emissivity \\
\hline $\begin{array}{l}\text { Zirconia, } \\
7 \pi)\end{array}$ & $\begin{array}{c}127 \\
1727\end{array}$ & $\begin{array}{c}1.6 \\
\quad 1.8\end{array}$ & 5.924 & $\begin{array}{r}518 \\
616\end{array}$ & $\begin{array}{l}0.86 \\
0.07\end{array}$ \\
\hline $\begin{array}{l}\text { Sapphire. } \\
\mathrm{Al}_{2} \mathrm{O}_{3}\end{array}$ & $\begin{array}{c}127 \\
1727 \\
\end{array}$ & $\begin{array}{l}32.4 \\
22.7 \\
\end{array}$ & 3.960 & $\begin{array}{c}959 \\
11,299 \\
\end{array}$ & \\
\hline Rhenium & $\begin{array}{c}127 \\
1727 \\
\end{array}$ & $\begin{array}{r}46.1 \\
54.2 \\
\end{array}$ & 21,036 & $\begin{array}{l}142 \\
174 \\
\end{array}$ & 0.8 \\
\hline $\begin{array}{l}\text { Multiolayer } \\
\text { Insulat. }\end{array}$ & $\begin{array}{c}127 \\
1727\end{array}$ & ${ }^{a} 0.045,5.7$ & 969 & 1172 & 0.1 \\
\hline
\end{tabular}

The material thermal properties of the various model components are shown in table I. The table shows the thermal conductivity, density, specific heat. and emissivity of zirconia, sapphire, rhenium, and the multilayer insulation. Little experimental data exists for zirconia and sapphire at temperatures above $1227^{\circ} \mathrm{C}$ : therefore, extrapolated values were used at the higher temperatures. The thermal model contained curves, as a function of temperature, of the thermal conductivity and specific heat for zirconia, sapphire and rhenium. The model also contained curves of emissivity but for only zirconia and sapphire. The emissivity curve for sapphire was assumed to be that of zirconia. All other material properties were held constant throughout the temperature range. It should be noted that the material properties of the MLI shown in the table are for an assumed mean temperature of $1093^{\circ} \mathrm{C}$.

A typical solar orbit of $60 \mathrm{~min}$ on-sun followed by a $30 \mathrm{~min}$ eclipse was assumed for the transient thermal analysis. $2000 \mathrm{~W}$ of solar flux was assumed incident to the inlet face of the RSC. Allowing for reflection losses and flux extractor efficiency, $1700 \mathrm{~W}$ was assumed to transmit through the crystal and project onto the inside surface of the engine receiver cavity. Single crystal materials currently being considered for the RSC are theoretically transparent to the solar spectrum at all wavelengths up to 5 to $6 \mu \mathrm{m}$. The assumption that all available energy above $5 \mu \mathrm{m}$ is absorbed in the RSC resulted in $\sim 8 \mathrm{~W}$ (out of $1700 \mathrm{~W}$ ) heing absorbed by the crystal. To account for this absorption. a thermal flux boundary condition of $1175 \mathrm{~W} / \mathrm{m}^{2}\left(8 \mathrm{~W} / 6.81 \times 10^{-3} \mathrm{~m}^{2}\right)$ was placed on the inlet face of the RSC.

As previously mentioned, ANSYS currently does not model radiation transmission through solids. As a result, an alternative tool was needed to model the radiation transmitted through the RSC and flux extractor. The solar flux profile striking the engine cavity was calculated using Opticad ${ }^{\mathrm{TM}}$ as described by Wong in reference 5 . Wong developed a ray-trace model of a zirconia RSC, flux extractor, and engine receiver cavity. The engine receiver cavity was divided into 16 sections in the ray-trace model. The average solar flux for each section was calculated then used as an internal surface thermal flux boundary condition for each corresponding section in the thermal model. The heat flux boundary condition is summarized in figure 3 and table II. 


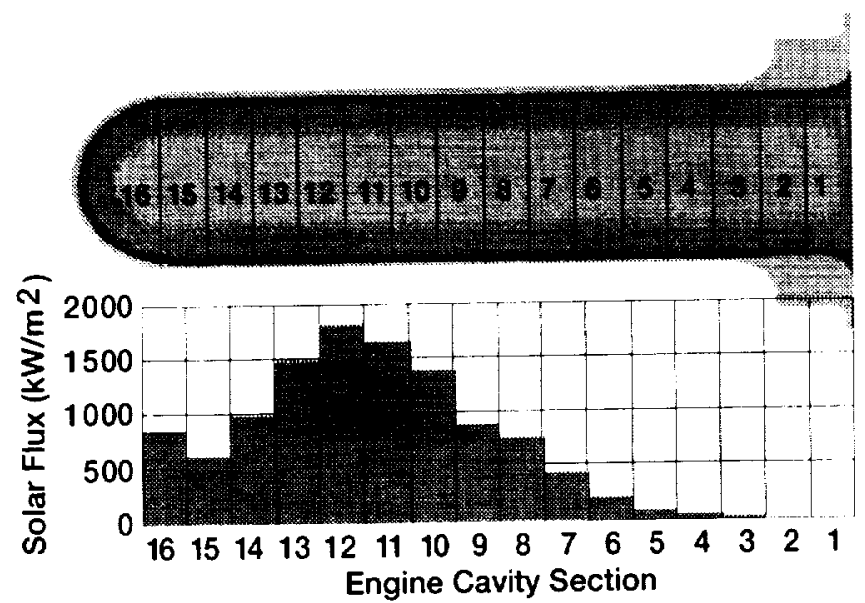

Figure 3.-Solar flux boundary conditions on inside suface of engine cavity.
TABLE II_-SOLAR FLUX BOUNDARY CONDITION ON INSIDE SURFACE OF ENGINE RECEIVER CAVITY

\begin{tabular}{|c|c|c|c|}
\hline $\begin{array}{c}\text { Cavity } \\
\text { section }\end{array}$ & $\begin{array}{c}\text { Solar } \\
\text { energy. } \\
\mathrm{W}\end{array}$ & $\begin{array}{c}\text { Area of } \\
\text { section. } \\
\mathrm{m}^{2}\end{array}$ & $\begin{array}{c}\text { Solar flux. } \\
\mathrm{W} / \mathrm{m}^{2}\end{array}$ \\
\hline 1 & 0.00 & $1.392 \times 10^{3}$ & 0 \\
\hline 2 & 0.00 & $1.392 \times 10^{-3}$ & 0 \\
\hline 3 & 3.81 & $1.392 \times 10^{-3}$ & 2.737 \\
\hline 4 & 5.24 & $1.392 \times 10^{-3}$ & 3.764 \\
\hline 5 & 11.20 & $1.392 \times 10^{-3}$ & 8.046 \\
\hline 6 & 28.36 & $1.392 \times 10^{3}$ & 20.374 \\
\hline 7 & 59.82 & $1.392 \times 10^{3}$ & 42.974 \\
\hline 8 & 105.69 & $1.392 \times 10^{-3}$ & 75.927 \\
\hline 9 & 123.21 & $1.392 \times 10^{-3}$ & 88.513 \\
\hline 10 & 192.32 & $1.392 \times 10^{-3}$ & 138.161 \\
\hline 11 & 229.61 & $1.392 \times 10^{3}$ & 164.950 \\
\hline 12 & 253.56 & $1.392 \times 10^{-3}$ & 182.155 \\
\hline 13 & 207.09 & $1.392 \times 10^{3}$ & 148.772 \\
\hline 14 & 137.74 & $1.392 \times 10^{-1}$ & 98.951 \\
\hline 15 & 87.10 & $1.392 \times 10^{-3}$ & 62.572 \\
\hline 16 & 247.25 & $2.929 \times 10^{-3}$ & 84.414 \\
\hline
\end{tabular}

An IR loss submodel was created to account for the infrared radiation loss that will be transmitted from the engine receiver cavity, through the crystal, and back out to space. A short cylinder, as shown in figure 2. was placed at the axial location along the flux extractor at the point of maximum flux extraction. The short cylinder communicaltes with the engine receiver cavity via a radiation link. There are no other thermal links to the short cylinder. The cylinder temperature is set to $23^{\circ} \mathrm{C}$ and acts as a heat sink. The size of the short cylinder was adjusted until the calculated IR loss was equivalent to the theoretical calculation developed by Buchele and documented in reference 3. The theorelical calculation was later verified using a NEVADA ${ }^{\mathrm{TM}}$ ray-trace model of the IR loss mechanism

Several radiation links exist in the model as shown in figure 2 . The following sets of surfaces thermally communicate via radiation: (1) the flux extractor, engine receiver cavity, and MLI, (2) the inlet face of the secondary concentrator. MLI, and an external heat sink, and (3) the engine receiver cavity and the IR loss submodel cylinder.

\section{Thermal Analysis}

The objective of the thermal analysis was to determine the maximum temperatures, temperature gradients, and heat flows for the RSC and flux extractor in a typical solar thermal propulsion application.

Figure 4 shows the temperature profile along the centerline of the flux extractor and RSC for sapphire and zirconia. For both materials, the maximum temperature is expected to reach roughly $1800^{\circ} \mathrm{C}$ at the tip of the flux extractor. The melting points of sapphire and zirconia are $\sim 2027$ and $2715^{\circ} \mathrm{C}$, respectively. The maximum temperature gradient occurs across the transition between the RSC and flux extractor

Figure 5 is a plot of the maximum temperature difference as a function of time. The temperature difference was calculated between two nodes on the centerline axis of the concentrator/extractor separated by a distance of $\sim 35 \mathrm{~mm}$. The plot shows that the temperature difference is expected to be $250^{\circ} \mathrm{C}$ higher for zirconia than for sapphire.

Figures 6 to 10 present a series of thermal plots showing how a sapphire RSC is expected to heat-up over 2 orbits and one additional on-sun period. Figure 11 presents the average and maximum sapphire crystal temperatures in a graphical format. As shown in figure 11 , the thermal model predicts that it will take $\sim 3$ orbits to achieve steady-state (within a repeatable band of) temperatures.

Table IIl shows heat flows and temperatures for both a sapphire and zirconia RSC after two orbits and one additional on-sun period. The largest differences are shown in the shaded rows in the table. The primary difference in temperature between the two materials is that the sapphire concentrator inlet face will operate almost $200{ }^{\circ} \mathrm{C}$ hotter than the zirconia concentrator due to sapphire's higher thermal conductivity. The conduction loss through the sapphire material is expected to be roughly $60 \mathrm{~W}$ larger than that of zirconia. 


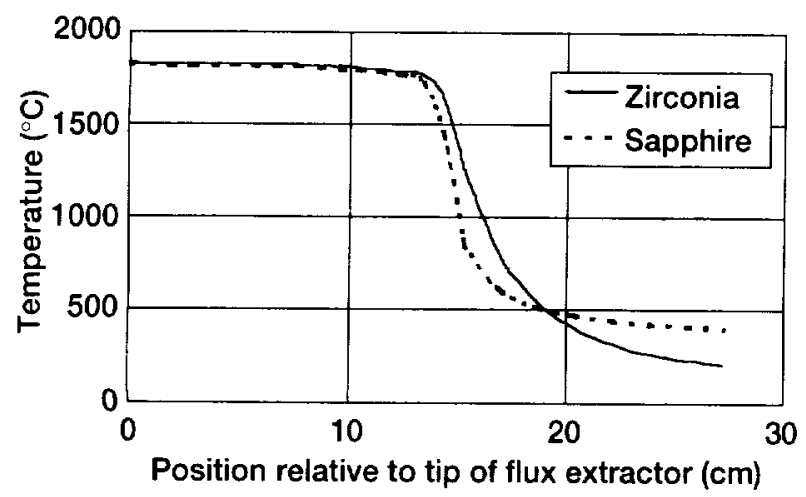

Figure 4.-Temperature along the centerline of the flux extractor and RSC vs position.

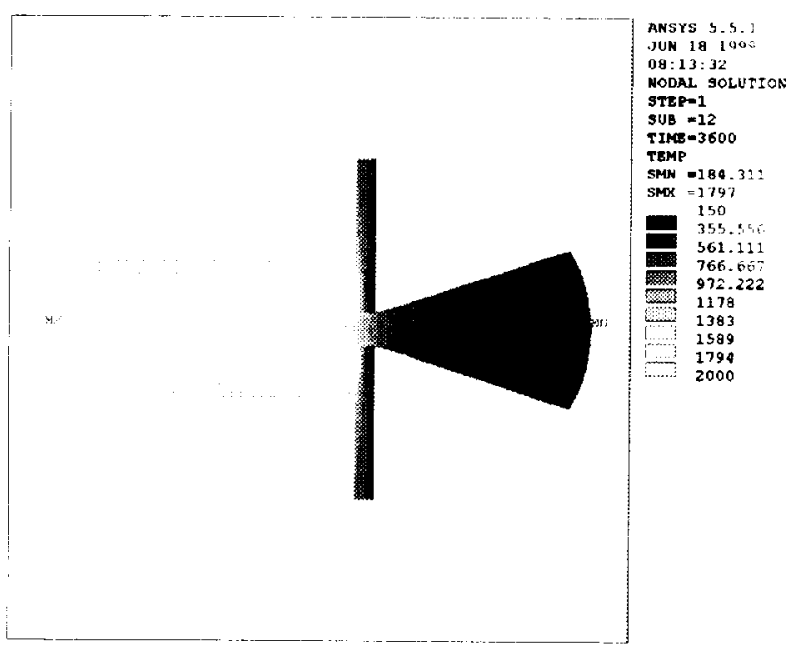

Figure 6.-Sapphire temperature after one 60-minute on-sun period.

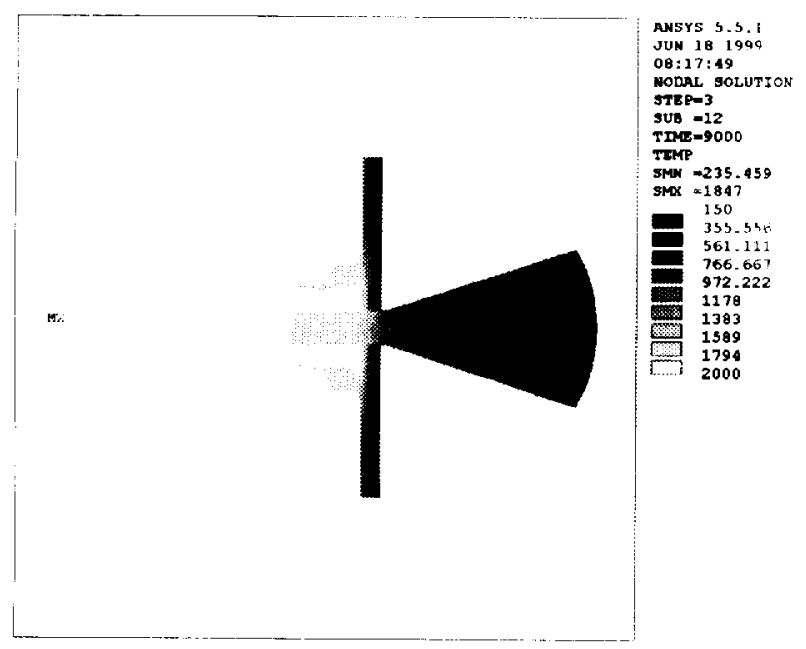

Figure 8.-Sapphire temperatures after one orbit and additional on-sun period.

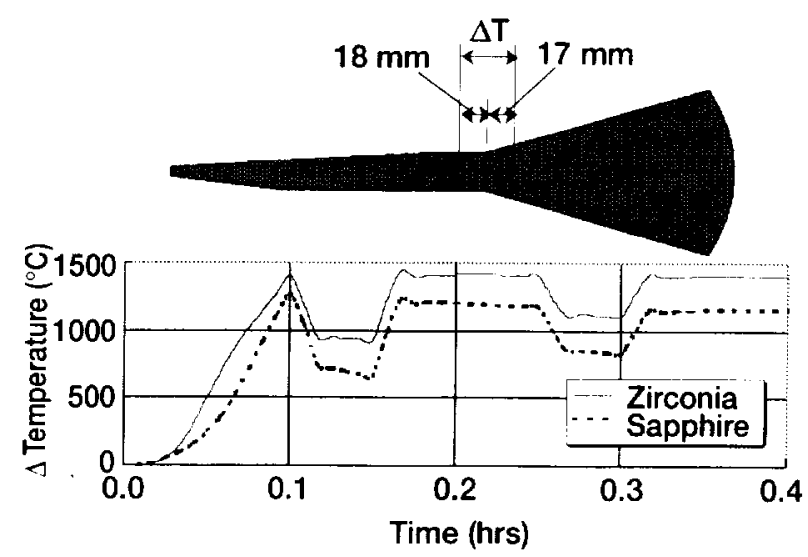

Figure 5.-Temperature difference across the concentrator/extractor vs position.

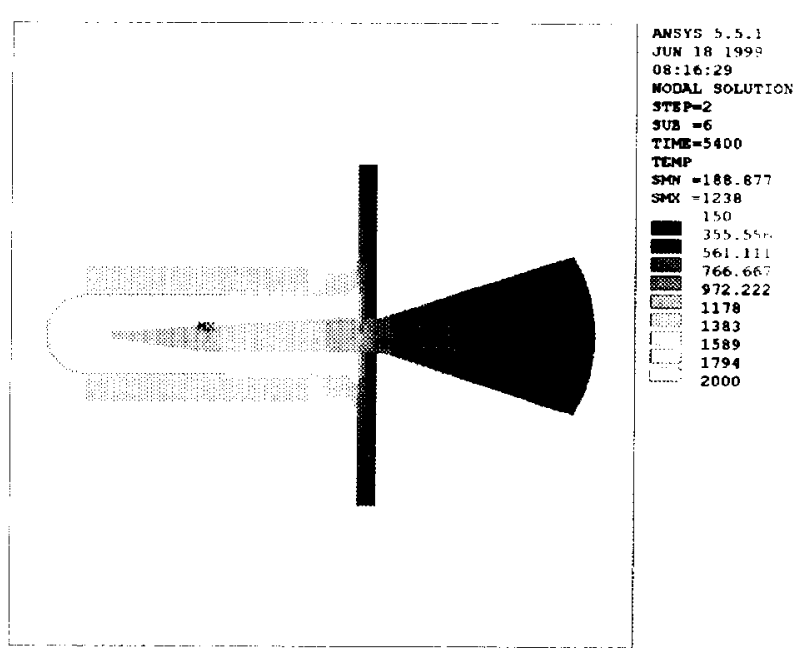

Figure 7.-Sapphire temperature after one orbit (on-sun + eclipse).

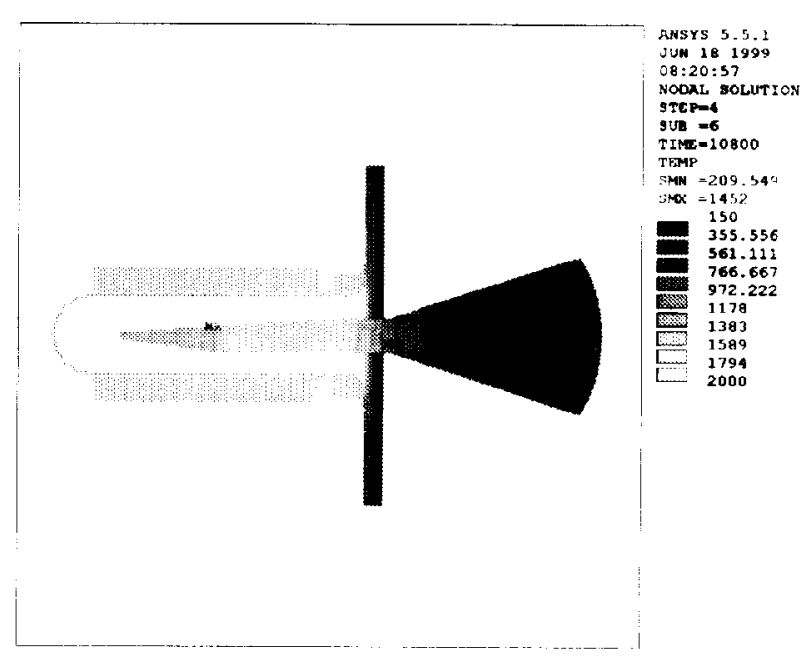

Figure 9.-Sapphire temperatures after two orbit. 


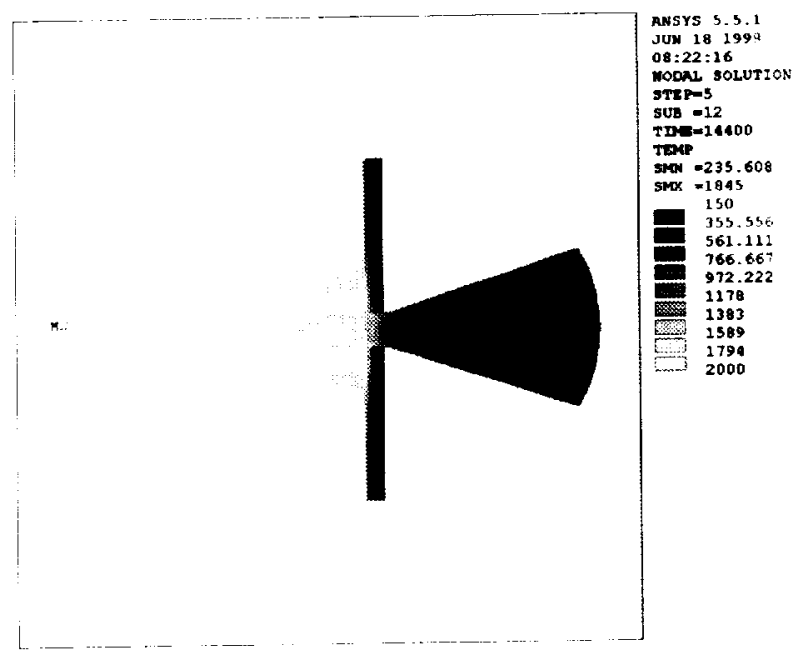

TABLE III.- HEAT FLOWS AND TEMPERATURES AFTER TWO ORBITS AND ONE ADDITIONAL

ON-SUN PERIOD

\begin{tabular}{|l|c|c|}
\hline Parameter & Sapphire & Zirconia \\
\hline $\begin{array}{l}\text { Radiation loss from RSC inlet } \\
\text { surface and MLI, W }\end{array}$ & 179 & 121 \\
\hline IR loss from receiver. W & 1444 & 1450 \\
\hline $\begin{array}{l}\text { Average concentrator inlet surface } \\
\text { temperature, }{ }^{\circ} \mathrm{C}\end{array}$ & 406 & 211 \\
\hline $\begin{array}{l}\text { Maximum concentrator inlet surface } \\
\text { temperature, }{ }^{\circ} \mathrm{C}\end{array}$ & 407 & 215 \\
\hline Average cavity temperature. ${ }^{\circ} \mathrm{C}$ & 1803 & 1808 \\
\hline Maximum cavity temperature, ${ }^{\circ} \mathrm{C}$ & 1845 & 1847 \\
\hline Average tip surface temperature, ${ }^{\circ} \mathrm{C}$ & 1828 & 1830 \\
\hline
\end{tabular}

Figure 10.-Sapphire temperature after two orbit and one additional on-sun period.

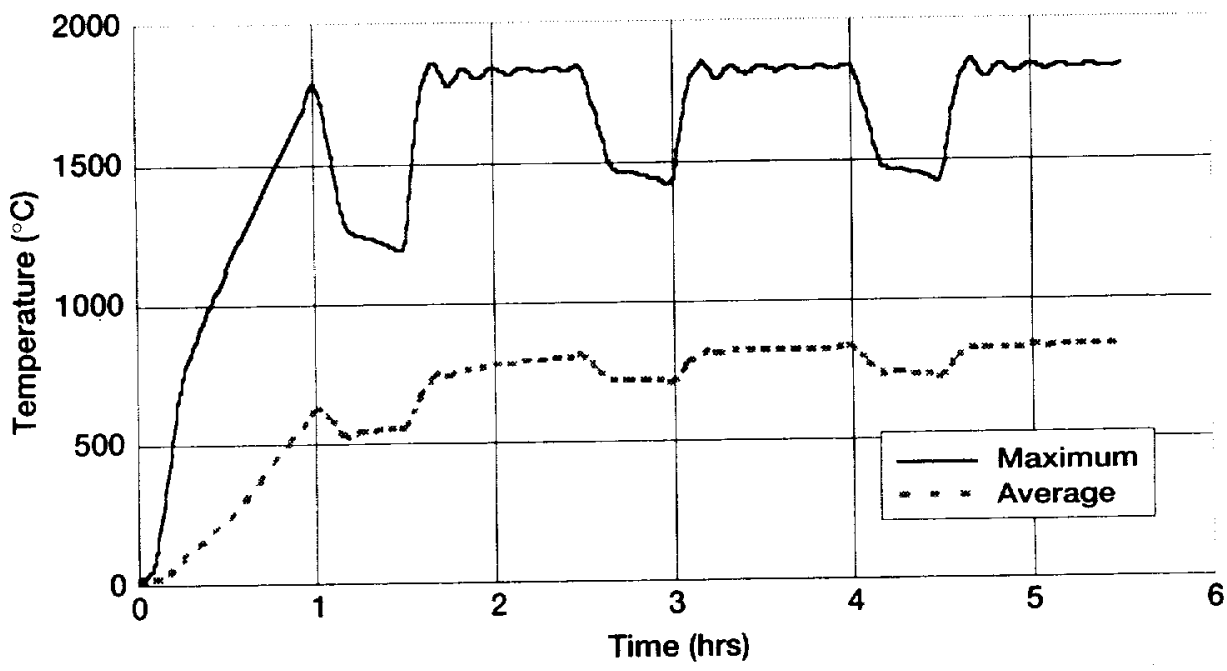

Figure 11.-Sapphire maximum and average crystal temperatures over three orbits and one additional on-sun period.

\section{Conclusion}

The model provides temperature and heat flow estimates of the engine receiver cavity, flux extractor, concentrator, and MLI. The preliminary analysis, which is affected by gross assumptions for material properties at high temperature (i.e. spectral absorption and thermal conductivity), indicates that large thermal gradients may develop in the crystal. A high temperature gradient can be expected where the flux extractor passes through the MLI. The temperature gradient is less severe for a sapphire secondary than for a zirconia secondary. Analysis indicates that sapphire is a more desirable material than zirconia for high temperature solar thermal applications. However, more data is required on the high temperature thermophysical properties of candidate optically clear single crystal materials to improve the accuracy of the thermal model. 


\section{References}

1. SPIE Milestone Series volume MS 106, Selected Papers on Nonimaging Optics, Roland Winston, Editor, 1995.

2. Ning, X., Winston, R., and O'Gallagher. J.: "Dielectric totally internally reflecting concentrators," Applied Optics, Vol. 26(2), pp. 300-305. Jan. 1987, 1987 Optical Society of America.

3. Soules, J.A., Buchele, D.R., Castle, C.H., and Macosko, R.P.: "Design and Fabrication of a Dielectric Total Internal Reflecting Solar Concentrator and Associated Flux Extractor for Extreme High Temperature (2500K) Applications," NASA Lewis Research Center, Cleveland, Ohio, NASA CR-204145, Nov. 1997.

4. Zhu, D., Jacobson, N.S., and Miller, R.A.: "Thermal-Mechanical Stability of Single Crystal Oxide Refractive Concentrators for High-Temperature Solar Thermal Propulsion." NASA Glenn Research Center. Cleveland, Ohio, NASA/TM-1999-208899, Feb. 1999.

5. Wong, W.A., Macosko, R.P.: "Refractive Secondary Concentrators for Solar Thermal Applications," NASA Glenn Research Center, Cleveland, Ohio, 1999-()1-2678. Aug. 1999. 
Public reporting burden for this collection of information is estimated to average 1 hour per response. including the time for reviewing instructions, searching existing data sources, gathering and maintaining the data needed, and completing and reviewing the collection of information. Send comments regarding this burden estimate or any other aspect of this collection of information, including suggestions for reducing this burden, to Washington Headquarters Services, Directorate tor Intormation Operations and Reports. 1215 Jefferson Davis Highway, Suite 1204. Arlington, VA 22202-4302, and to the Otfice of Management and Budget. Paperwork Reduction Project (0704-0188), Washington, DC 20503.

\begin{tabular}{|l|c|c|c|}
\hline 1. AGENCY USE ONLY (Leave blank) & $\begin{array}{c}\text { 2. REPORT DATE } \\
\text { July } 1999\end{array}$ & $\begin{array}{c}\text { 3. AEPORT TYPE AND DATES COVERED } \\
\text { Technical Memorandum }\end{array}$ \\
\hline
\end{tabular}

\section{TITLE AND SUBTITLE}

5. FUNDIMG NUMBERS

Transient Thermal Analysis of a Refractive Secondary Solar Concentrator

6. AUTHOR(S)

WU $-632-81-0 A-00$

Steven M. Geng and Robert P. Macosko

\section{PERFORMING ORGANIZATION NAME(S) AND ADDRESS(ES)}

National Aeronautics and Space Administration

John H. Glenn Research Center at Lewis Field

Cleveland. Ohio 44135-3191
8. PERFORMING ORGANIZATION REPORT NUMBER

$E-11811$

\section{SPONSORING/MONITORING AGENCY NAME(S) AND ADDRESS(ES)}

National Acronautics and Space Administration

Washington. DC 20546-00()1
10. SPONSORING/MONITORING AGENCY REPORT NUMBER

NASA TM-1999-209384

SAE 99-01-2680

\section{SUPPLEMENTARY NOTES}

Prepared for the 34th Intersociety Energy Conversion Engineering Conference sponsored by the Society of Automotive Engineers, Vancouver, British Columbia, Canada, August 1-5, 1999. Steven M. Geng, NASA Glenn Research Center, and Robert P. Macosko, Analex Corporation. Brook Park, Ohio 44142. Responsible person, Steven M. Geng, organization code 5490, (216) 433-6145.

12a. DISTRIBUTION/AVAILABILITY STATEMENT 12b. DISTAIBUTION CODE

Unclassified - Unlimited

Subject Category: 20

Distribution: Nonstandard

This publication is available from the NASA Center for AeroSpace Information, (301) 621-0390.

13. ABSTRACT (Maximum 200 words)

A secondary concentrator is an optical device that accepts solar energy from a primary concentrator and further intensifies and directs the solar flux. The refractive secondary is one such device; fabricated from an optically clear solid material that can efficiently transmit the solar energy by way of refraction and total internal reflection. When combined with a large state-of-the-art rigid or inflatable primary concentrator, the refractive secondary enables solar concentration ratios of 10.000 to 1 . In support of potential space solar thermal power and propulsion applications, the NASA Glenn Research Center is developing a single-crystal refractive secondary concentrator for use at temperatures exceeding $2000 \mathrm{~K}$. Candidate optically clear single-crystal materials like sapphire and zirconia are being evaluated for this application. To support this evaluation, a three-dimensional transient thermal model of a refractive secondary concentrator in a typical solar thermal propulsion application was developed. This paper describes the model and presents thermal predictions for both sapphire and zirconia prototypes. These predictions are then used to establish parameters for analyzing and testing the materials for their ability to survive thermal shock and stress.

\section{SUBJECT TERMS}

Solar power; Solar thermal propulsion; Solar concentrators; Secondary concentrators

15. NUMBER OF PAGES 13

16. PRICE CODE

$\mathrm{A} 03$

\begin{tabular}{|c|c|c|}
\hline $\begin{array}{c}\text { 17. SECURITY CLASSIFICATION } \\
\text { OF REPORT } \\
\text { Unclassified }\end{array}$ & $\begin{array}{c}\text { 18. SECURITY CLASSIFICATION } \\
\text { OF THIS PAGE } \\
\text { Unclassified }\end{array}$ & $\begin{array}{c}\text { 19. SECURITY CLASSIFICATION } \\
\text { OF ABSTRACT } \\
\text { Unclassified }\end{array}$ \\
\hline
\end{tabular}

NSN 7540-01-280-5500
Standard Form 298 (Rev. 2-89)

Prescribed by ANSI Std. Z39-18 298-102 